\title{
Schopenhauer en "Lo fatal" de Rubén Darío
}

1.-Darío, en la Historia de mis libros, considera "Lo fatal" como una poema algo inusitado: ". . y en "Lo fatal", contra mi arraigada religiosidad, y a pesar mío, se levanta como una sombra temerosa un fantasma. de desolación y de duda."1 Nos habla luego de sus temores ante la muerte, de sus incertidumbres sobre el más allá y de la impotencia de la filosofía para darnos adecuada respuesta.

"Lo fatal" es la expresión sentida - muy sentida - de sus dudas sobre la vida, sobre la ubicación del hombre en el cosmos: qué somos, adónde vamos, de dónde venimos. $Y$ por suerte para la poesía española, Darío. ha abandonado aquí, como complacidamente lo advierte Amado Alonso, ${ }^{2}$ la ya vieja retórica modernista. Los lectores me agradecerán una nueva oportunidad de leer el poema:

Dichoso el átbol que es apenas sensitivo y más la piedra dura, porque ésta ya no siente, pues no hay dolor más grande que el dolor de ser vivo, ni mayor pesadumbre que la vida consciente.

Ser, y no saber nada, y ser sin rumbo cierto, y el temor de haber sido $y$ un futuro terror... y el espanto seguro de estar mañana muerto, y sufrir por la vida y por la sombra y por

lo que no conocemos y apenas sospechamos, y la carne que tienta con sus frescos racimos y la tumba que aguarda con sus fúnebres ramos, iy no saber adónde vamos, ni de dónde venimos. .!

1. En Obras completas (Madrid: Aguado, 1950), pp. 222-223.

2 Materia y forma en poesía (Madrid: Gredos, 1965), p. 328.

3 Cantos de vida y esperanza, en Poesias completas (Madrid: Aguilar, 1954), pp. 778-779. Copio de esta edición de A. Méndez Plancarte para mayor seguridad en los textos. 
El tono característico de "Lo fatal", que sólo se repite en algunos otros poemas de Cantos de vida y esperanza, tono pesimista y amargo, ha llevado a los críticos al análisis de presuntas fuentes: literarias, científicas y filosóficas. Amado Alonso, muy consciente de la limitación de esta clase de estudios, relaciona el poema con un soneto de Miguel Angel, especialmente con los dos versos que subrayo:

Caro mèll sonno e più l'esser di sasso mentre ch'el danno e la vergogna dura. Non veder, non sentir m'è gran ventura; peró non mi destar, deh! parla basso. ${ }^{4}$

Reconoce Alonso un tono diferente en Miguel Angel, casi humo. rístico - desdeñoso diría yo-; y considera que Darío ha tomado de su fuente la idea central impregnándola de un sentimiento distinto: "EI sentimiento poetizado en "Lo fatal" no se prostó nadie." El Estudio de similitudes y diferencias sirve a Amado Alonso para darnos una magistral lección sobre el aprovechamiento estilístico de las fuentes literarias.

Arturo Marasso, casi al mismo tiempo, investiga extensamente las fuentes de "Lo fatal". Acepta la indicación de Alonso y agrega cantidad de nombres de autores cuyas obras tienen cierto contacto con los versos fundamentales de Darío: Ruskin, Mallarmé, Boscán, Homero, Erasmo, Fernán Pérez de Oliva, Sófocles, Marco Tulio, el libro de Job, Hugo, Laforgue, Lupercio Leonardo de Argensola, Tibulo. Se detiene en una posible fuente científica, la Ciencia experimental de Claude Bernard, especialmente en lo referido a la clasificación de la sensibilidad (consciente, inconsciente, irritabilidad). Para ajustar el poema a esa clasificación, fuerza Marasso la lectura del tercer verso: "Que no hay dolor más grande que el dolor de ser vivo", viendo en él una mención a los animales. Me resulta más útil para mi propósito citar la siguiente observación general de Marasso: "Decharme ha estudiado las ideas pesimistas acerca de la vida y de la condición humana en Eurípides; no las dilataremos con citas de autores hasta llegar a Schopenhauer y Hartmann, que Darío conocía". ${ }^{6}$

En un artículo sobre la "Estilistica de las fuentes literarias", Emilio Carilla discute respetuosamente las atribuciones de Alonso y de Marasso:

4 Alonso, op. cit., p. 331.

5 Ibid., p. 333.

- Arturo Marasso, Rubén Dario y su creación poética (Buenos Aires, 1954), p. 281. 
"Sobre esta base diré que ni la cuarteta de Miguel Angel ni la obra ae Claudio Bernard me convencen como fuentes indudables de "Lo fatal" ... porque no se apoyan en reconocibles rasgos expresivos, rasgos que serán siempre las pruebas inequívocas (o más fundadas) de una fuente literaria." 7 Establece luego una clara relación entre "Lo fatal" y "A Phocas el campesino" de Darío y concluye: "un dolor, un gran dolor es el estímulo inmediato de "Lo fatal". Sentimiento por la enfermedad o, más exactamente, por la muerte del hijo. El misterio de la vida y de la muerte revelado (una vez más, pero ahora con acumulados terrores) en el niño."8

Carilla no sustituye unas fuentes por otras. Pero en el apéndice nos acerca textos de Nietzsche, Amiel, Baudelaire y Richepin, por presentar unas pocas ideas comunes con "Lo fatal". En el caso concreto de Nietzsche, sólo se trata de aproximaciones muy vagas, basadas en términos comunes. Riesgosa tarea, pues los textos provienen de traducciones. Así, por ejemplo: "Pues si todo es fatal ¿qué puedo yo sobre mis actos?"'

Atina Carilla al conferir importancia al sentimiento básico del poema. Nuestros estudios de fuentes literarias, por deficiencias del método, tienden a valorar demasiado ideas y palabras prescindiendo del tono. ¡Y qué nos queda como reminiscencia de las Rimas de Bécquer, por ejemplo, sino una vaga melodía, un impreciso sentimiento de desazón amorosa y de dolor! Si el mismo Darío se inspiró en Wagner para su "Marcha Triunfal", es inútil buscar en las ideas y las palabras trazas de esa influencia. El tono humorístico del soneto de Miguel Angel y el frío acercamiento científico de Bernard nada tienen que ver con la profunda emotividad de esta poesía.

Con respecto a Bernard, lo único que sobrevive en un análisis crítico, como posible influencia, es el ordenamiento de los seres vivos de acuerdo con la sensibilidad. Ordenamiento tan frecuente en textos clásicos y modernos que su enumeración fatigaría. Creo importante advertir que en todos los casos, ya se refleje en ese orden una visión pagana o cristiana del hombre, al llegar a él desde la piedra, se habla de una ascensión o de una suma, no de una resta. Es una valoración del hombre frente a los seres vivos, una afirmación optimista. Aunque a veces, en algunos autores (como en San Agustín) haya sombras de duda. En Darío el orden es negativo; descendemos de la piedra al

7 En Cuadernos hispanoamericanos (Madrid, 1964, número 180), p. 6.

8 Ibid., p. 8.

9 Ibid., Apéndice, p. 16. 
hombre. Si es que alguna fuente existe, ésta tiene que presentar parecida visión.

Nietzsche, como lo recibió el 98 español y el modernismo hispanoamericano, abona la ladera optimista de la vida. No hay mucho de Nietzsche en Datío; ${ }^{10}$ y lo poco que hay acompaña la exaltación pletórica de la vida instintiva, ${ }^{11}$ la defensa del individuo, la utopía, el alba de oro.

"Lo fatal" está impregnado de pesimismo, de "desolación y de duda". Para un hombre de la generación de Darío, el pesimismo no necesita remontarse a etapas del Renacimiento ni a la ciencia experimental. Tiene la más cercana formulación -y la mejor- en Schopenhauer. Marasso advierte relaciones del filósofo alemán y el poeta en "Divagación" de Prosas profanas (en cuyo prólogo Darío cita a Scho. penhauer) y en "Poema de otoño" de Otros poemas.

Schopenhauer se contrapone a Nietzsche, a pesar de lo mucho en común. En El Mundo como voluntad y representación, I, 56, encuentro este claro antecedente de "Lo fatal":

Pues a medida que el fenómeno de la voluntad se hace más perfecto, el dolor se hace también más evidente. En la planta no hay todavía sensibilidad, ni por consiguiente, dolor (en sentido estricto). Los animales inferiores, infusorios y radiarios, no son capaces más que de un grado mínimo de dolor; hasta en los insectos, la facultad de sentir y de padecer es todavía muy limitada.

Con el perfecto sistema nervioso de los vertebrados llega a gran altura y se eleva en la proporción en que se desenvuelve su inteligencia. A medida que el conocimiento se hace más claro y que la conciencia crece, el dolor aumenta, y llega a su grado supremo en el hombre. En él es tanto más violento cuanto más lucidez de conocimiento y más elevada inteligencia posee. El genio es quien más padece. ${ }^{12}$

Falta en el texto de Schopenhauer la mención a la piedra. Pero no en el resto del capítulo y del libro; por el contrario, uno de sus ejemplos

10 Ver González Sobejano, Nietzsche en España (Madrid: Gredos, 1967), pp. 197-205.

11 Rubén Benítez, "La expresión de lo primitivo en Estival de Dario", en Revista Iberoamericana (XXXIII, 64, 1967), pp. 248-249.

12 Cito por la edición de La España Moderna (Madrid: s/a. Tomo II, libro cuarto, parágrafo 56), pp. 216-217. He utilizado también, para confrontar la cita, la excelente versión inglesa de E. F. J. Payne (Colorado, 1958). El texto aparece en tomo I, p. 310 . Tiene un utilísimo indice de nombres y de temas. 
más característicos es el de la piedra que no se mueve por voluntad sino por accidentes externos.

No niego la posibilidad de que haya habido en Darío una reminiscencia de "l'esser di sasso" de Miguel Angel. Es lo único de similar que entre las dos poesías veo. Porque en el texto de Miguel Angel, el muerto habla desde la piedra, desdeñoso del mundo, de la vergüenza y el daño de la vida terrena; y en ese sentido se complace ahora en en no ver ni sentir. Exalta, por consiguiente, valores cristianos: desprecio por el mundo, halago del más allá. Pero no rechaza, ni podría hacerlo sin negar la imagen y semejanza de Dios, el haber tenido conciencia. El verso fundamental del poema de Darío nos da la clave del dolor humano: "Ni mayor pesadumbre que la vida consciente". No es el dolor de sentir, sino el de tener conciencia. El sentir es negativo porque a medida que la sensibilidad crece, crece la conciencia y el dolor. El árbol siente menos; la piedra sintió alguna vez (ver Marasso p. 279), pero ya no siente. No puede entenderse el sentido exacto de esa fatalidad del hombre sin el auxilio del texto de Schopenhauer.

En Schopenhauer se dan, pues, los elementos centrales del poema de Darío: el ordo naturae, con sentido negativo; la idea de que el hombre siente más porque tiene conciencia del dolor, y el tono pesimista. Creo indudable la relación entre estos textos.

Darío tiene, además, clara idea de que su poema revierte el sentido del ordo naturae. A tal punto, que la inversión constituye uno de los recursos más evidente de su estilo, y el que produce un disloque grotesco, trágico, en el lector ingenuo. El poema, como lo advierte Marasso de pasada, se inicia con una recordación del Beatus ille ("Dichoso el árbol"). Beatus ille inverso, diferente del que celebra la vida contemplativa. Ante ese primer verso (o primeras palabras), el espiritu del lector se prepara para una celebración de la felicidad. Las negaciones reiteradas van quitándonos esa primera ilusión: apenas, ya no, $n$. Afirmación y negación que se organizan a lo largo del poema: ser $y$ no saber; ser sin rumbo; lo que no conocemos, y no saber adónde, ni de dónde. También en las dos imágenes más elaboradas de la poesía, una afirmación de vida aparece anulada con la idea de la muerte: $Y$ la carne que tienta con sus frescos racimos; $y$ la tumba que aguarda con sus fúnebres ramos. Sólo se afirma, sin contraposición alguna, lo negativo: el temor de baber sido, y un futuro terror... / y el espanto seguro de estar mañana muerto / y sufrir por la vida y por la sombra y por... Es evidente en estos versos, que es la conciencia del hombre la razón del dolor. Es el sufrimiento de pensar en nuestro destino, de ignorar 
nuestra suerte. Y Darío podría haber seguido enumerando razones del dolor humano. Le resulta innecesario: ha sabido dar al instrumental por, repetido y extrañamente encabalgado en el verso siguiente, un valor tan absoluto, que sentimos no importante el término de esa preposición. El hombre sufre por.

Darío ha triunfado sobre Schopenhauer, ha conseguido transmitirnos, no un pensamiento, sino una angustia personal que lo confirma. No dice: expresa. Los aciertos de esa expresión, tan bien estudiados por Amado Alonso, convencen más que un tratado filosófico.

RubÉN BEníteZ

University of California, Los Angeles 